\title{
A chassis exchange terminal to reduce truck congestion at container terminals
}

\author{
Rommert Dekker • Sander van der Heide • \\ Eelco van Asperen • Panagiotis Ypsilantis
}

Published online: 4 May 2012

(C) The Author(s) 2012. This article is published with open access at Springerlink.com

\begin{abstract}
Truck congestion for container terminals seems to be a worldwide unwanted phenomenon. In this paper we present and analyze a chassis exchange terminal concept to reduce the congestion. The terminal works as a kind of extended gate of a group of traditional container terminals. During the night containers are collected from these container terminals using chassis (or trailers). In daytime these containers on chassis are then collected and exchanged with export containers also on chassis. By exchanging the chassis we avoid extra handling of containers. As connecting and disconnecting to a chassis can be done in a short time, the chassis exchange terminal increases handling capacity substantially during peak hours. In this paper we analyze the concept for the Maasvlakte container terminals in Rotterdam. We investigate both the effect on waiting time, as well as the environmental effects.
\end{abstract}

Keywords Queuing - Congestion · Container terminal - Truck transport

R. Dekker $(\bowtie) \cdot$ S. van der Heide

Erasmus School of Economics, Erasmus University Rotterdam, Burg. Oudlaan 50,

Rotterdam, The Netherlands

e-mail: rdekker@ese.eur.nl

URL: http://people.few.eur.nl/rdekker/

S. van der Heide

e-mail: sander154@gmail.com

E. van Asperen

Center for Maritime Economics \& Logistics, Erasmus University Rotterdam,

Burg. Oudlaan 50, Rotterdam, The Netherlands

e-mail: vanasperen@ese.eur.nl

URL: http://people.few.eur.nl/vanasperen/

P. Ypsilantis

Rotterdam School of Management, Erasmus University Rotterdam, Burg. Oudlaan 50,

Rotterdam, The Netherlands

e-mail: pypsilantis@rsm.nl 


\section{Introduction}

World-wide container transport has shown large growth over the past decades and due to ongoing containerization of cargo flows and further globalization this growth is expected to continue in the years to come. To accommodate the volume demand container-ship sizes have shown an increase and will continue to increase. As ocean waterways offer endless capacity it has been recognized that the decisive factor for accommodating and enabling the volume growth will be land-based infrastructural capacity. The availability of sufficient access to deep-sea terminals and hinterland infrastructure (road, rail, waterways) is likely to be the key driver to the success of future container operations.

Although European legislation is strongly advocating the increase of the market shares for rail and barge (driven by environmental and congestion arguments) the industry and many legislators at the same time recognize that enforcing the desired modal-shift will take years.

A lack of available and efficient capacity of these modalities, a strong merchant driven European market (which reduces shipping-lines influence on even realizing this imposed modal-shift), not all ports having inland waterways and the ongoing development of environmental friendly truck technology favors the more practical approach of the co-modality thinking (=optimization within existing modalities) as the best way for achieving an optimal and sustainable logistic system. Therefore it is very likely that road-haulage will remain an important mode that deserves and desires further attention and it is for this reason that we like to present an alternative solution that will have a positive impact on road-congestion, sustainability, service integrity and the operational cost of container inland truck operations.

The proposed Chassis Exchange Terminal (CET) is an off-dock terminal where container trucks consisting of a tractor and a trailer will exchange their trailer (here also called chassis) with containers instead of unloading and loading containers at the deep-sea terminal's premises. It is a new solution for Western-Europe, so no scientific literature exists about it.

The outline of this paper is as follows. First we describe the typical working of a container terminal, next we outline the CET $\odot$ c solution and thereafter we quantify its effects both from a cost, environmental and efficiency perspective.

\section{The typical working of (an import) container terminal}

\subsection{Description}

The main business of a container terminal is the transfer of containers between different transport modes. This can be the transshipment of containers from vessel to vessel, or the link between the hinterland and intercontinental shipment. Hinterland transport of containers can be accommodated by barge, train and truck, depending on the accessability by rail and water. In this article the emphasis will be on the bottlenecks at the truck side of the process. Overviews of container transport have been given by Vis and de Koster (2003), Notteboom (2004) and Steenken et al. (2004). 
We will describe the process at a semi-automated container terminal in Rotterdam from ship to truck in four steps.

The first step is the transfer of containers from ship to berth using container cranes. During the second step containers are moved from the berth to the stack using AGVs (Automated Guided Vehicles). The third step is the storage of the containers for a certain amount of time. Stacking and unstacking (retrieval) is done via Automated Stacking Cranes (ASCs) that roll over several rows of containers. The final step is the delivery/receipt of the containers by trucks or intermodal transport. Straddle Carriers transport the containers between trucks and the stack, because the present stacking cranes cannot do so. This process is reversed in case of an export container. The gate and the processing capacity (ASC and SCs) at the terminals are bottlenecks in the whole truck transport process.

The truck handling process includes the following: Pre-announcement, check of documents, clearance, trucker is permitted to drop off and/or pick up a container, arrives at gate, check of container + trucker, trucker goes to exchange point, unloads container, loads container, trucker goes to gate, customs check, final check and leaves for destination.

\subsection{Problems at the hinterland interface of container terminals}

In Europe $76.6 \%$ of the inland transportation of goods is done by trucks (European Union Road Federation (ERF) 2009). This large amount of trucks causes for congestion at terminal gates at peak moments. Container transport is a steady growing sector. This increase will lead to even more congestion at the terminal gates. A study in the Los Angeles and Long Beach ports showed that $40 \%$ of the trucks wait for more than $2 \mathrm{~h}$ at the terminal gates, leading to 3.7 million hours of waiting per year for the LA/LB area alone (Barber and Grobar 2001). Although this is an old study and there have been some improvements, the transport has grown as well and the congestion problem seems to be all over the world. Waiting often happens in a queue with the engines of trucks idling. This causes for significant amount of emissions. If no action will be taken it is likely that the waiting times and the emissions associated with this will increase significantly in the future.

Other problems that parties involved in the transport of containers via truck face are:

- Low utilization of the terminal during nights and weekends.

- Road-congestion: mainly during rush hours it is likely that truckers are faced with road congestion. Mainly the roads in the harbor area face these problems with both freight and commuter traffic on the road at the same time. This congestion increases the trip time of truckers and makes trip planning difficult.

- High turnaround times: the turnaround times of truckers visiting seaport terminals are dependent on the capacity of container terminals on container moves, on the land side, and on the distribution of this capacity in the different processes within the terminal. In a merchant haulage situation the transport towards the hinterland via trucks does not mainly concern the seaport terminal authorities since higher waiting times of truckers do not have a direct cost on the 
container terminal. Thus it is only of indirect interest of the seaport terminals to increase their capacity to handle peaks more efficiently.

- Equipment failure: the failure of terminal equipment and especially the ITsystems can cause for unforeseen delays. This is a problem that will only occur sporadically, but can cause long delays.

\section{The CET}

The Chassis Exchange Terminal (CET) is an off-dock container terminal where truckers exchange chassis (also called trailers). It is being developed by Mr Broek (a former executive of APL Europe). A bottleneck trucking companies face is combining an import and export container into one trip within a reasonable turnaround time. The turnaround time increases if a trucker has to visit different sites on a terminal or two different terminals. Instead of visiting a seaport container terminal during peak hours, a trucker exchanges a chassis with a container at the CET. The CET will use off-peak hours to transport the containers from and to the seaport terminals. The CET is based upon two principles, a stacking method called 'stack on wheels' and a shared chassis pool. Stack on wheels is a stacking method where containers are placed directly on a chassis at the terminal. This stacking method requires a lot of space but has as advantage that the handling is reduced to a minimum (Henesey 2006). Due to the land requirements it is a less used stacking method and only a small number of seaport container terminals in the United States use it (the APL terminal at Long Beach, see Fig. 1). Stack on wheels requires a

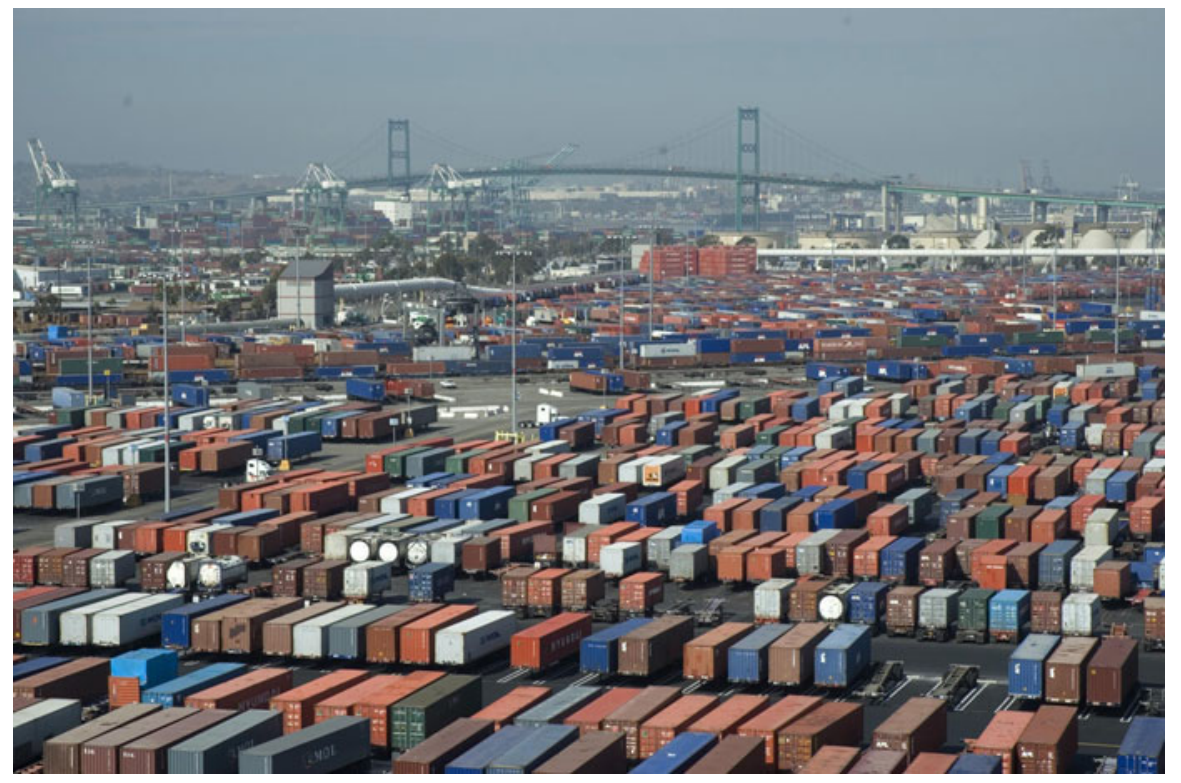

Fig. 1 Port of Long Beach, California. Image: Charles Csavossy I Wikimedia Commons 


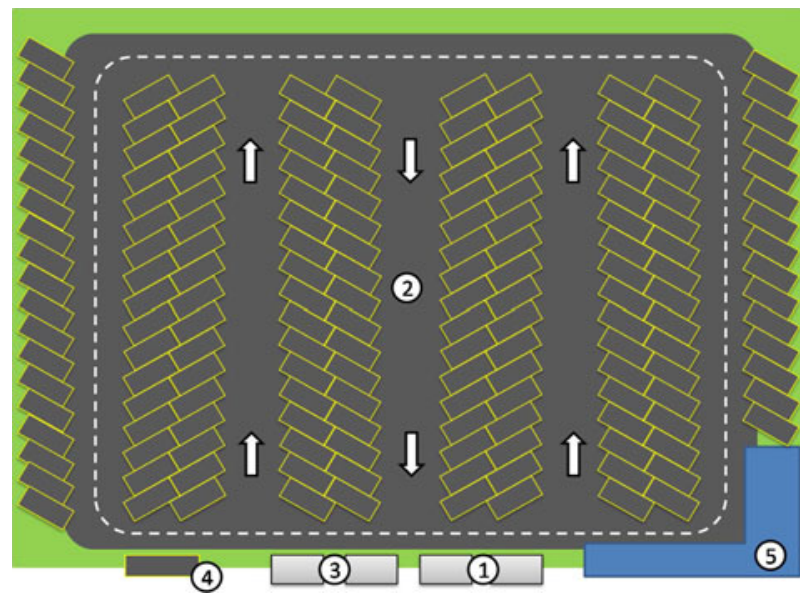

Fig. 2 Layout CET (van der Heide 2010)

terminal to have chassis ready for the placement of containers; this is where the shared chassis pool comes in place. The CET accommodates a large chassis pool that visitors of the terminal can use. The CET is intended to be used by a limited number of truck companies which will also be shareholders, in order to avoid cost allocation issues and to increase security of the whole process. One of its shareholders will be a chassis leasing company, which will provide the chassis and which will use the CET for inspection and repairs.

\subsection{The process}

The CET has two processes, viz.:

- Chassis exchange: truckers deliver a chassis with an export container and collect a chassis with an import container.

- Shuttle service between CET and seaport terminals: off-peak shuttle service to transfer export/empty containers to the seaport terminals and pick-up import containers for transport towards the hinterland.

The exchange of chassis is a process that will take place during the daytime. Likely the hours to receive containers of a CET will be between $5 \mathrm{~h}$ and $19 \mathrm{~h}$. Figure 2 shows the proposed layout of the CET.

The process will be discussed step by step following the numbers in Fig. 2.

1. Gate-in: Trucks arriving at the CET will be scanned by the automated gate system. By scanning the truck the system can couple it to an announced visit and guide the truckers to the right location on the terminal. As the truck passes the gate it will receive a ticket with instructions. These instructions include the location to place its current chassis and the location of the new chassis. Truckers that are not recognized by the system are redirected to a parking place (4). This ensures that there are no delays at the gates. 
2. Switching chassis: Trucks first proceed to the designated space to uncouple their current chassis. After this is done the truck proceeds to the designated parking space where the chassis with the import container is located. Here the new chassis is coupled to the truck and after that the truck can proceed to the gate-out.

3. Gate-out: Trucks arriving at the gate-out will be scanned by the automated gate system. The system checks if the right chassis has been coupled to the truck, if this is the case the truck can proceed toward its hinterland destination.

The entire process is expected to take approximately 15 min (Broek 2009), which is much less than times quoted at container terminals. Due to the fact that the terminal does not rely on any terminal equipment it lacks any bottlenecks involved with this and therefore ensures a fast turnaround time that only depends on the speed of the trucker himself.

The transfer of the containers from and to the CET is done at off-peak hours. Normally these are at night from $21 \mathrm{~h}$ till $5 \mathrm{~h}$. During these hours a pool of tractors with the chassis will shuttle between the CET and the different seaport terminals. Since the CET has a large number of containers to drop-off and pick-up it can easily combine trips to ensure the fastest turnaround times. Due to its larger scale, the CET faces less problems in combining trips to the same destination. The number of round trips visiting different locations is limited to a small number of dissimilarities in import and export containers or different destinations. By combining trips and using off-peak hours the turnaround time at the seaport terminals will be lower.

\subsection{Advantages}

The CET is beneficial to several parties within the container transport. The main advantage of the CET is peak shaving. By taking a substantial part of the daily truck visits from the seaport terminal to the CET the peak moments will be quieter. This shift requires that seaport terminals are open at night. The change is beneficial to both visitors of the CET and the seaport terminals. Visitors of the seaport terminal have to share the available capacity with fewer truckers and thus will experience shorter waiting times. Visitors of the CET have a shorter turnaround time due to the method used that does not rely on terminal personnel or equipment. Accompanied with shorter turnaround times is less waiting and thus idle engine time. This will lead to fewer emissions.

Further advantages for the parties involved in CET are:

- Increase in daily amount of trips: due to the shorter and more predictable truck turnaround times at the CET truckers can be back on the road sooner. Hence they can possibly avoid the rush hour and they will shorten their total trip time. This will allow them to do more trips on a day compared to truckers visiting the seaport terminals.

- Less empty trips: currently it is common that part of the trip of truckers to the seaport terminals is empty. This is primarily done since it is hard to combine an export and import container without increasing the trip times significantly. The CET offers trucking companies one destination to deliver and pick-up 
containers. This will increase the utilization of the capacity a truck will have on a round trip. Using a smaller amount of trips for the same capacity will have a positive effect on the environment as well.

- Increase of workload in off-peak hours for seaport terminals: the CET will take a portion of the daily trips away from the peak hours and move it to the off-peak hours. The shuttle transfer between the CET and the seaport terminals will occur during the night, when the capacity of seaport terminals currently remains unutilized. Seaport terminals have tried several methods to make this shift before. Los Angeles for example tried Truck Appointment Systems at first, but since these were not working they introduced a payment system for trucks visiting during the peak hours. This made off-peak hours more interesting (Giuliano et al. 2008).

\section{Effect of CET on gate congestion}

\subsection{The problem}

Arrivals of trucks at a container terminal vary in time over the days. A typical day pattern of truck arrivals at a particular terminal in the port of Rotterdam is as shown in Fig. 3.

This pattern reflects data from 2010. The terminal is closed for trucks on Saturday afternoon and Sunday until $18 \mathrm{~h}$ (ships are still served). During the weeknights it is open, in order to reduce day congestion at the terminal and the connecting A15 highway. Yet few truckers arrive during the night and a project called "Night distribution" appeared to be not that successful, despite several incentives given. The reason is that truckers mostly cannot deliver their containers during the night. In fact most distribution centers open after $7 \mathrm{~h}$ and do not accept containers before $8 \mathrm{~h}$. Truckers want to work during day-time. They may be willing to start early, even at $5 \mathrm{~h}$ to avoid congestion, but due to labor regulations, they can only work $12 \mathrm{~h}$ a day. The afternoon peak can be explained from truckers who want to pick-up a container for the next day. They then park their loaded truck at their company and continue the following day. There may be some international truckers

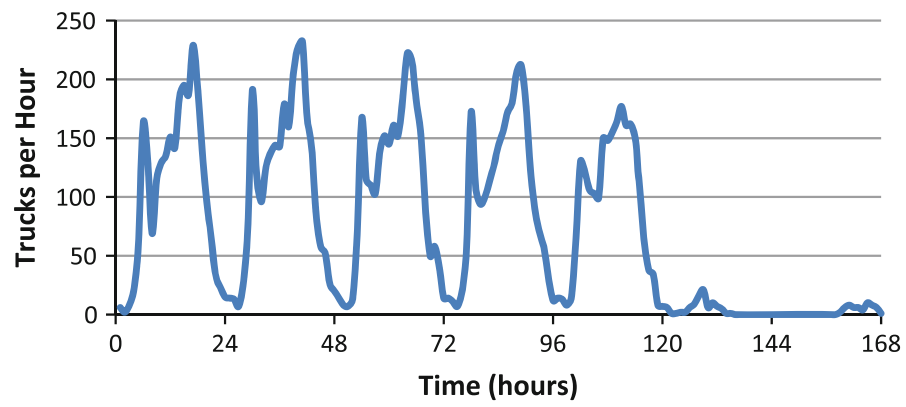

Fig. 3 Weakly arrival pattern of trucks at the terminal 
arriving at night, but their number is small. This phenomenon is not uncommon in the world, although many terminals are not open during the night. It also depends on the area the terminal serves and the modal split. Export and transshipment terminals suffer less from these problems.

The terminal applies several working shifts to accommodate demand. The shifts the terminal operates are (according to their 2009 labor agreement) an early morning shift (from 7.15 to 15.30), a midday shift (from 11.30 to 19.45), an evening shift (15.15-23.30) and finally a night shift (23.15-7.30). Shifts lasts for $8 \mathrm{~h} 15 \mathrm{~min}$ and have a lunch break of half an hour. Quite often the breaks during shifts increase the congestion. Accordingly, it is more difficult for a container terminal to accommodate a time-varying demand than e.g. a call center which can work with part-timers. Therefore the terminal will not try to accommodate the highest demand rate, but somewhere below that value, also because a container terminal does not have to pay penalties for long delays in truck handling. A final problem is that demand over the weeks may vary substantially. E.g. the number of trucks may change by $20 \%$ over the weeks. Since the economic crisis in 2009 , the demand has gone down somewhat compared to 2008 when they even handled 16,000 trucks a week.

It is clear that because of the time varying demand and the difficulties to accommodate capacity to that, as well as the problem of having breaks, there can be substantial queues of trucks. This is a common phenomenon at container terminals all over the world. Usually truckers have to accept it, but it is clear that overall supply chain costs can be reduced if there is much less waiting.

\subsection{The effect of the CET}

It is not that easy to evaluate the effect on the terminal, as there can be several bottlenecks in the handling processes. Since the CET plans to retrieve containers from the terminals between 19 and $5 \mathrm{~h}$, a timing that corresponds with the trough in the truck arrival pattern, it is clear that the CET allows for a substantial reduction on trucks served during the peak hours. It is however beforehand not clear how the daily pattern will be once the CET has been introduced. The CET is meant for a number of large trucking companies in the area of Rotterdam, with the idea that they will be able to do several more round trips per day. The investment in the CET is much less interesting in trucking companies who do only one or two trips to the terminals per day. Accordingly, it seems realistic that the arrival rate will be lower over the whole day between 5 and $21 \mathrm{~h}$.

What will be the effect of a lower arrival rate? It is well-known from queuing theory that even a small reduction of workload can reduce the waiting lines considerably. Presently, some 2,400 trucks arrive per day at the terminal. It is the idea that the CET will handle some 480 trucks per day which would otherwise go to this terminal. The effect of such a $20 \%$ decrease depends on the average load factor of the terminal, but that varies over the day.

Calculations can be done in two ways, viz. analytically or by simulation. A challenge for the analytical calculations is that the arrival rate varies over the day and surpasses the capacity. One could evaluate the time dependent process or use an approximation. Several approximations are possible in case of the so-called $M(t) / M /$ 
c queue, i.e. with a time varying arrival rate, an exponentially distributed processing time and c servers. We compared some approximations and obtained satisfying results, which are reported in Witte (2010). Another issue, however, is that the straddle carriers are not the only bottleneck; there is also a gate process and a retrieval process from the automated stack area. Processing times of the latter do depend on whether a ship is handled at the same time. Finally processing times also depend on the tasks the truck may have: dropping off and/or picking up a container, and whether it carries or picks-up one 40 or 45 foot container, or two 20 foot, or a combination.

A simulation model was therefore developed to investigate the effect of CET on the waiting time of trucks visiting the terminal. Full details are given in Ypsilantis (2010). The model assumed the straddle carrier capacity as the main bottleneck of the total process and was structured as follows. Two zones were considered, the waiting zone with infinite service lanes and the transfer zone with number of service lanes equal to the number of straddle carriers operating. The former serves for waiting until trucks are permitted to enter the latter, in which trucks can pick up or drop off containers. In the waiting zone the queue develops and in the transfer zone trucks are served. After their service trucks exit the system.

The arrival of trucks was generated assuming that the inter-arrival times followed an exponential distribution with non-constant arrival rate $\mathrm{m}(\mathrm{t})$, which followed the truck arrival pattern shown in Fig. 3. The arriving trucks were further discriminated on the processes they had to go through, picking up or/and dropping of containers and on the number of container carried. The discrimination was based on the statistical analysis performed on the terminal's data for 2010 . In short, $50.1 \%$ of trucks had only to pick up containers with only $10 \%$ picking up 2 containers, $23.6 \%$ of trucks had only to drop of containers with only $9 \%$ dropping of 2 containers and $26.3 \%$ of trucks performed combined trips with only $3 \%$ carrying more than one container in each process.

The parameter $m(t)$ can be calculated from $m(t)=(D A \cdot A P(t))^{-1}$, where $D A$ is the average number of truck arrivals per day and $A P(t)$ the percentage of arrivals per time unit. The handling process within the transfer zone was simulated considering the straddle carrier capacity of the terminal in a FIFO basis. Regarding the straddle carrier capacity on the terminal there are two shifts in each day that should be considered, the day shift, between 07:00 and 21:00, when up to 15 straddle carriers operate and the night shift, between 21:00 and 07:00, when only up to 12 straddle carriers operate. In reality, the actual number of straddle carriers operating within the transfer zone can be increased, even to more than 15 straddle carriers, in cases of many truck arrivals which might otherwise lead to high waiting times for the truckers. This is achieved by assigning transfer jobs to straddle carriers other than the ones originally assigned to the transfer zone. Each straddle carrier was assumed to have an average capacity of 15 moves per hour, so the service time within the transfer zone for one handling was generated assuming a uniform distribution with average $4 \mathrm{~min}$ and range equal to $1 \mathrm{~min}$.

The model was developed in Mathworks, MATLAB v.7.9 environment and was run in an AMD Athlon II X2 B24, 2.99 GHz processor with 3.00 GB of RAM. Two cases were examined to investigate the effect of CET on the waiting times of 
Table 1 Daily average waiting time (in min) pattern and confidence intervals

\begin{tabular}{|c|c|c|c|c|c|c|c|c|c|}
\hline \multirow[t]{2}{*}{ Hour } & \multicolumn{2}{|c|}{ Normal } & \multicolumn{2}{|c|}{ With CET } & \multirow[t]{2}{*}{ Hour } & \multicolumn{2}{|l|}{ Normal } & \multicolumn{2}{|c|}{ With CET } \\
\hline & Mean & $\begin{array}{l}\text { St. } \\
\text { deviation }\end{array}$ & Mean & $\begin{array}{l}\text { St. } \\
\text { deviation }\end{array}$ & & Mean & $\begin{array}{l}\text { St. } \\
\text { deviation }\end{array}$ & Mean & $\begin{array}{l}\text { St. } \\
\text { deviation }\end{array}$ \\
\hline 01 & 0.00 & 0.00 & 0.00 & 0.00 & 13 & 10.48 & 0.18 & 0.38 & 0.03 \\
\hline 02 & 0.00 & 0.00 & 0.03 & 0.00 & 14 & 17.99 & 0.19 & 0.78 & 0.05 \\
\hline 03 & 0.00 & 0.00 & 0.02 & 0.00 & 15 & 31.52 & 0.28 & 1.51 & 0.09 \\
\hline 04 & 0.00 & 0.00 & 0.03 & 0.00 & 16 & 49.45 & 0.35 & 3.37 & 0.16 \\
\hline 05 & 0.03 & 0.00 & 0.03 & 0.00 & 17 & 73.03 & 0.41 & 7.22 & 0.24 \\
\hline 06 & 2.70 & 0.06 & 0.91 & 0.03 & 18 & 98.22 & 0.48 & 14.47 & 0.30 \\
\hline 07 & 17.50 & 0.19 & 5.55 & 0.13 & 19 & 110.95 & 0.53 & 23.73 & 0.35 \\
\hline 08 & 12.26 & 0.19 & 1.03 & 0.05 & 20 & 106.64 & 0.56 & 25.96 & 0.37 \\
\hline 09 & 1.90 & 0.10 & 0.03 & 0.00 & 21 & 85.58 & 0.58 & 18.90 & 0.26 \\
\hline 10 & 0.36 & 0.02 & 0.07 & 0.00 & 22 & 50.28 & 0.58 & 6.68 & 0.14 \\
\hline 11 & 0.79 & 0.03 & 0.17 & 0.01 & 23 & 14.90 & 0.42 & 3.74 & 0.12 \\
\hline 12 & 2.03 & 0.06 & 0.38 & 0.02 & 24 & 0.56 & 0.07 & 2.51 & 0.03 \\
\hline
\end{tabular}

truckers visiting the terminal, the terminal normal and the terminal with CET; in the latter lowered truck arrival rates were considered. Some 1,000 runs were performed for each case; each run simulated one working day of the terminal and lasted approximately $2 \mathrm{~s}$. For every hour we show in Table 1 the average and standard deviation of the mean waiting time of trucks arriving in that hour. Since the arrival rate of trucks during the night is low, at least much lower than the capacity of the transfer zone, no warming up period was needed. Every day the terminal starts with an empty queue which develops during the day and then diminishes again after the evening peak in the arrival pattern.

For the terminal normal case an average daily truck rate of 2,400 trucks was considered, while for the terminal with CET case this rate was reduced by 480 truck arrivals during the day shift while they were evenly redistributed in the night shift. It follows from the generation procedure (using a nonhomogeneous Poisson process) that the observed total number of trucks visiting the terminal for every individual run varies. This variation affects the workload on the transfer zone and is in line with the variations observed in the actual truck visits among the different days. In our simulation we observed a total number of arriving trucks per day ranging from 2,241 to 2,585 trucks, with an average of 2,400 and standard deviation equal to 48.8 trucks. The average waiting times over a day are quite dependent on the total number of trucks arriving that day.

Below, in Fig. 4, we show the results of simulations on the effect of the CET on the average waiting time at a container terminal assuming only the straddle carriers as the main bottleneck. It is clear that the waiting times will be much less when using the CET. For our case the total average waiting time, that truckers faced during their visits, was reduced by $83.2 \%$ from 1,565 to only $263 \mathrm{~h}$ by redistributing $20 \%$ of trucks arrivals from the morning shift to the night shift. 


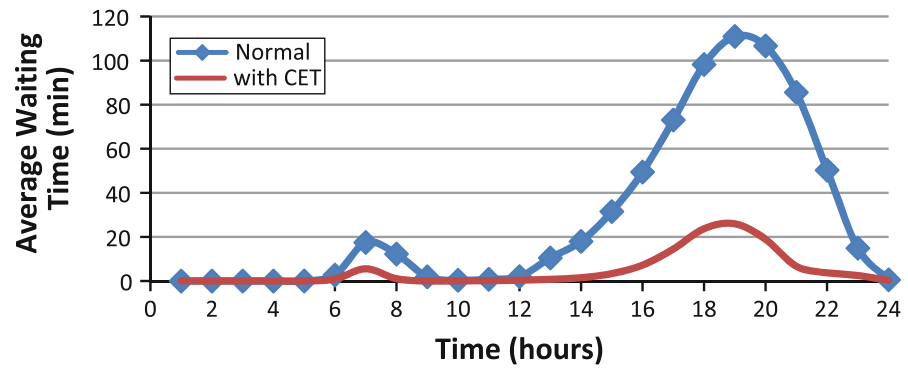

Fig. 4 Daily average waiting time pattern

The results have to be evaluated with care. From our data analysis it appears that there are large variations (some $20 \%$ ) in the number of trucks arriving per week (due to holidays, ships arriving earlier or later and changes in the shipping schedules). The recent economic crisis had reduced this number substantially in 2009 from the peak levels in 2008, but in 2010 the number of arriving trucks has recovered and surpassed all previous levels. Moreover, queues are also caused by breakdown of terminal systems, which can have a dramatic effect. Finally, the terminal has expanded with another terminal and some customers have switched to that terminal. Accordingly, the truck load is quite variable. Yet it is clear that the CET will have a positive effect. There is one paradox however. If the CET reduces the waiting times substantially, then it will no longer be cost-effective as then all users will avoid the CET as they have to pay for it and not for the standard terminal treatment.

The results of our simulation model presented in Fig. 4 and Table 1 are difficult to validate with the current performance levels of the terminal for two main reasons. First, the turnaround times of trucks visiting the terminal cannot be exclusively divided in waiting and handling times which is the main assumption of the model, since several other processes take place before the container picking up or dropping off performed by the straddle carriers such as the route plan creation, inspections etc. Second, the number of active straddle carriers serving the transfer zone of the terminal also follows the arrival pattern of trucks to the terminal. In periods with low truck arrival rates the straddle carriers not serving trucks are used for the reshuffling of containers in the storage area. The actual turnaround time pattern of trucks visiting the terminal is confidential. Comparing the simulation results with the actual performance we observe that for the morning peak the average waiting time is quite higher than the one presented in Fig. 4, due to the shift change for the straddle carriers operators. In fact actual practice offers room for improvement. On the other hand, for the evening peak the average waiting times are significantly lower, since more straddle carriers are assigned to exclusively serve the increased arriving trucks transfer needs. As the scope of the model is to assess the effect of a small reduction of truck arrival rates, we decided not to build in more detail in the model, as that would imply making many assumptions, which would make the model less transparent. 


\section{Effect of CET on load factor to terminals}

At the moment there are three terminals in Maasvlakte area: ECT Delta Terminal, the APM Terminal and the EUROMAX terminal. The ECT Delta terminal in fact consists of three terminals, DDN, DDE and DDW, with terminals working for one or more clients. The expansion to Maasvlakte 2 foresees even more terminals: Rotterdam World Gateway, an APM terminal and, possibly, even a sixth terminal.

In order to reduce road congestion and gas emissions, one wants to have high truck load factors. This means that one would like to see trucks making round trips loaded on both ways. In general trucks can carry one 40 or 45 foot containers or two 20 foot containers. There are some exceptions, the so-called LZV truck that can carry three 20 foot containers, but its share is at the moment below $0.1 \%$, so we will leave it out of consideration.

Several agencies are monitoring truck load factors, but before going into detail, we have to make some remarks. Western-Europe has a substantial trade imbalance with Asia. This implies that many containers return empty to Asia. For truckers it does not matter whether they transport empty or full containers, yet a truck with an empty container is officially registered as an empty truck, as in legal terms the truck with a container is a single entity and that entity is empty. The next thing is that in the registrations there is no difference between a 20 foot or a $2 \times 20$ foot loaded truck.

The official truck load factor for trucks moving to the terminals is $60 \%$. The official TEU load of trucks carrying containers back and forth is 2.3 TEUs. This implies that from the 4 TEUs slots on a truck with trailer making a return trip to the terminal, only about $60 \%$ is used. The next thing to consider is the TEU Factor which indicates the ratio of 20 -foot and 40 -foot containers while talking about a number of TEU. The current TEU factor is 1.7 , this means that $70 \%$ of the containers is 40 -foot and $30 \%$ is 20 -foot. (thenortherngateway.co.uk, 26-04-2010)

The reason for a low truck load factor is that there is no suitable return trip at the moment the trip is executed, so a triangulation cannot be done (this is a trip followed by a dead trip and next a return trip). So when a container is brought to the Maasvlakte, there are no suitable pick-up containers. This may be due to the fact that such a job is only later available, or that it is at another terminal. It is clear that an exact analysis is very difficult. Yet it will be clear that the CET can improve the truck loadfactor, as trips to different terminals can be easily executed through the CET. Moreover, as the CET combines trips of a whole day into the night also time consolidation is possible. The exact gain a company is likely to make, depends on the number of trips it is making and its current percentage empty trips.

\section{Cost analysis CET}

The development of the CET requires a substantial piece of land: the storing of containers on chassis requires a lot more space than other, more common, stacking methods. The location of the CET should be close to the seaport terminal, because then a lot of transfers can be made during one night with a limited number of truckers. The land in the seaport area, however, is rather expensive, but locating it 
much further away would increase the transportation cost substantially. Contrary to traditional terminals, the CET does not require special land preparations or terminal equipment. This makes the development cheaper opposed to inland terminal solutions with quaysides or train depots. Required investments are:

- Preparing terrain: pavement of the terrain, assigning parking lots for chassis, fencing and lightning;

- Automated gates system at the entrance and exit;

- Office building for personnel;

- IT hardware and software for terminal operations.

The investment costs needed for the CET are much less compared to other inland terminal solutions such as train or barge terminals. These inland terminals require ground preparations to support the weight of multilevel stacking and also the construction of a quayside or a train terminal with cranes (IBI Group and MacDonald 2006). These investments are quite expensive and can cost several millions. These costs are not necessary for the CET.

The operational costs involve personnel, land, terminal maintenance, IT, the chassis pool and trucks and truckers for the nightly shuttle service. One of the main uncertain cost elements is the land lease which will have to be paid. Revenues from the CET users must cover these costs in return for the beneficial service offered to them. Rates of about 45 euro per container are being mentioned. Given that number the CET will run break even.

\section{Environmental impact of CET}

The CET is likely to have several positive effects on the environment. This is done by reducing the terminal load during peak hours and by increasing the average load factor during round trips.

By shifting trucks from the seaport terminals toward the CET the peaks that seaport terminals face are softened. This lowers the waiting times of truckers and thus decreases the amount of hours that truck engines run idle. The truckers that are going to the CET instead of the seaport terminals are not depending on the terminal equipment and thus are back on the road faster cutting time of their trip and thus exhaust fewer emissions per trip.

The CET gives trucking companies one place to send truckers to for both delivering and collecting containers, where these containers have to go to different seaport terminals. In a normal situation it would be faster and cheaper to split these trips while the CET allows trucking companies to combine these containers to one trip. This increases the use of available capacity and also decreases the amount of trips needed and thus the emissions.

Following is a simulation of the difference that the higher utilization of capacity has on the number of trips, emissions and costs (the effects at the terminal are not taken into account). The simulation uses EURO V trucks, currently the most clean truck type available in Europe, and an average trip distance of $75 \mathrm{~km}$. The tool used is from the Dutch Transport Institute NEA (Table 2). 
Table 2 Emission comparison normal versus CET for 100,000 TEU

\begin{tabular}{llll}
\hline & Normal & CET & Difference (\%) \\
\hline Utilization of capacity & $61 \%$ & $82 \%$ & \\
Loaded trips & $85 \%$ & $95 \%$ & \\
Number of trips & 96,432 & 64,185 & -33.4 \\
CO2 emissions $(\mathrm{kg})$ & $6,577,279$ & $4,377,817$ & -33.4 \\
NOX emissions $(\mathrm{kg})$ & 17,587 & 11,706 & -33.4 \\
PM10 emissions $(\mathrm{kg})$ & 176 & 117 & -33.5 \\
Transport costs & $€ 10,546,770$ & $€ 7,387,035$ & -30.0 \\
Total Costs & $€ 12,539,870$ & $€ 8,713,636$ & $-30.5 \%$ \\
\hline
\end{tabular}

Source: NEA Vergelijkingskader Modaliteiten v1.4b (NEA 2004)

Loaded trips is the fraction of trips on which a container is transported, while utilization measures the fraction of cargo weight versus weight capacity. The figures are the assumed increases by using the CET. The result is that the number of needed trips is reduced by $1 / 3$. This reduction reflects in the emissions as well and the costs are reduced by $30 \%$. Trucking companies can thus spend up to 120 Euros on around trip to CET, due to the difference in costs when visiting CET and seaport terminals. Considering its cheap cost structure, the CET is expected to provide its service far cheaper than this and thus there will be a healthy profit margin for trucking companies as well.

\section{Conclusions}

The Chassis Exchange Terminal (CET) is a new concept to reduce truck congestion at seaport container terminals and to improve truck efficiency in trips to these terminals. The main idea is to avoid extra crane handling by putting containers on a chassis and applying a chassis pool. The CET is fed from the container terminals during the nights, when these terminals encounter very low truck traffic. The stacking method requires more land, but it reduces the truck turnaround time substantially. Moreover, as there is no real handling bottleneck, it also removes uncertainty in the retrieval of containers, thus allowing truck companies to plan multiple trips from customers to the CET per day. Moreover, it allows for more loaded round trips, as trips to different locations can easier be combined. The higher trip loads will reduce the number of empty trips and thus substantially reduce greenhouse gas emissions.

Acknowledgments The authors would like to acknowledge the input from Mr. Broek, who is the inventor of the CET concept and has been the leading person in developing and realizing the concept.

Open Access This article is distributed under the terms of the Creative Commons Attribution License which permits any use, distribution, and reproduction in any medium, provided the original author(s) and the source are credited. 


\section{References}

Barber D, Grobar LM (2001) Implementing a statewide goods movement strategy and performance measurement of goods movement in California METRANS Transportation Center, Available through the National Technical Information Service

Broek (2009) Personal communication

European Union Road Federation (ERF) (2009) European road statistics 2008. In: 16th International Road Federation World Road Meeting 2009, Lisbon, Portugal

Giuliano G, Hayden S, Dell'aquila P, O'Brien T (2008) Evaluation of the terminal gate appointment system at the los Angeles/Long beach ports. METRANS Project 04-06

IBI Group, \& MacDonald HM (2006) Inland container terminal analysis. British Columbia Ministry of Transportation

Henesey LE (2006) Multi-agent systems for container terminal management. Doctoral thesis, Blekinge Institute of Technology

NEA (2004) Comparison framework modalities (Computer program in Dutch)

Notteboom TE (2004) Container shipping and ports: an overview. Rev Netw Econ 3(2):86-106

Steenken D, Voss S, Stahlbock R (2004) Container terminal operation and operations research a classification and literature review. OR Spectr 26:3-49

Van der Heide S (2010) Congestion problems at seaport terminals: comparing innovative solutions. MSc thesis Erasmus University Rotterdam

Vis IFA, de Koster R (2003) Transshipment of containers at a container terminal: an overview. Eur J Oper Res 147(1):1-16

Witte A (2010) Analytical queueing models for congestion at container terminals. BSc thesis, Econometrics and Operations Research Department of Erasmus University Rotterdam

Ypsilantis P (2010) Analysis on the impact of chassis exchange terminals on the overall performance of container terminals and transportation companies. MSc thesis Erasmus University Rotterdam

\section{Author Biographies}

Rommert Dekker is a full professor in operations research at the Econometric Institute of Erasmus University Rotterdam. He obtained his Ph.D. in operations research at the State University of Leiden, and his M.Sc. degree in industrial engineering from Twente University of Technology. He worked with Shell for 7 years on reliability and refinery logistics. His current research interests are: maintenance and logistics (inventory control, spare parts, ports, containers and reverse logistics). He has applied simulation models in various logistical problems.

Sander van der Heide obtained his M.Sc. degree in Economics \& Informatics from the Erasmus University Rotterdam.

Eelco van Asperen is a lecturer at the Center for Maritime Economics and Logistics, Erasmus University Rotterdam, The Netherlands. He graduated in Business Computer Science at Erasmus University Rotterdam in 1993. He worked in IT and then as an assistant professor at the Department of Computer Science and the Econometric Institute at Erasmus University Rotterdam. In 2009 he obtained his Ph.D. in Economics at the Erasmus University Rotterdam. His research focuses on simulation with applications in logistics.

Panagiotis Ypsilantis is a doctoral candidate at the Rotterdam School of Management of Erasmus University of Rotterdam. He obtained his MSc degree at the Econometric Department of Erasmus University of Rotterdam. His research interests are in modeling maritime logistics, container transport networks and reverse logistics. 